\title{
SALUD
}

\section{Neumonía asociada a la ventilación mecánica (NAVM) en una unidad de cuidados intensivos adultos, Hospital de Clínicas. Año 2016}

\author{
Zunilda Garay Duarte ${ }^{1}$
}

\section{Resumen}

Introducción: La neumonía asociada a la ventilación mecánica (NAVM) se define como la infección del tejido pulmonar que ocurre posterior a 48 horas de la intubación orotraqueal. Representa la infección hospitalaria más frecuente, asociándose con una elevada tasa de mortalidad, morbilidad y costos. En la última década se ha producido un rápido aumento de la tasa de resistencia entre los patógenos bacterianos recuperados en las unidades de Cuidados Intensivos. Los desafíos para la prevención de IAAS aumentan en una unidad de terapia intensiva, debido a la variedad de microorganismos, muchas veces multirresistentes, implicando en el uso de antimicrobianos de amplio espectro. Se caracteriza por realizar procedimientos invasivos para diagnosticar o posibilitar la cura del paciente, lo que torna el control de infecciones complicado. La NAVM es una complicación que ocurre en alrededor de 20-25 $\%$ de los pacientes ventilados durante más de 48 horas, con una incidencia de $1 \%$ adicional por cada día de ventilación mecánica. Las cepas productoras de carbapenemasas de tipo KPC se han diseminado por todo el mundo y Paraguay no es una excepción. Debido a los factores de riesgo vinculados a los cuidados de la salud en áreas cerradas y con procedimientos invasivos así como al uso de antibioticoterapia previa, constituye todo un desafío diagnóstico y terapéutico dado las escasas opciones disponibles, lo que obliga a optimizar el uso de los antimicrobianos así como a realizar combinaciones sinérgicas de los mismos que sólo en cierta medida han demostrado eficacia. Es una preocupación de la Organización Mundial de Salud, teniendo en cuenta que una mayor resistencia de los microorganismos a los antimicrobianos, genera enormes costos adicionales para los sistemas de salud, elevados costos para los pacientes y sus familias, y muertes innecesarias. Los objetivos del estudio fueron: determinar la incidencia de NAVM, la frecuencia por pacientes vigilados y el agente etiológico. Material y Método: Estudio descriptivo retrospectivo realizado desde enero a diciembre del año 2016, en pacientes internados en la Unidad de Cuidados Intensivos de Adultos (UCIA) con ventilación mecánica invasiva (VM) con criterios de infección asociados a este procedimiento invasivo. Los datos se obtuvieron

1. Control de Infecciones Intrahospitalarias, Hospital de Clínicas. Facultad de Ciencias Médicas de la Universidad Nacional de Asunción, Paraguay.

E-mail: zunichamorro82@hotmail.com

DOI: $10.26885 /$ rcei.foro.2017.152 
de la vigilancia activa y selectiva de IAAS asociadas a dispositivos invasivos. Variables: Edad, diagnóstico de ingreso, agente etiológico. Se utilizó planilla de denominadores, ficha de caso, planilla mensual. Definiciones operacionales: Es la infección que se presenta en un paciente con ventilación mecánica que se utilizó en el plazo de 48 horas antes del inicio de la infección, se consideró a aquel paciente con cuadro clínico de neumonía y presencia de infiltrado nuevo o progresivo y persistente, consolidación y cavitación. Análisis estadísticos: Tasa de NAV: $\mathrm{N}^{\circ}$ de infecciones asociada a dispositivo/ $\mathrm{N}^{\circ}$ de días-dispositivo $\times 1.000$ y por 100 pacientes vigilados

Se calculó la tasa de incidencia por 1000 días procedimiento y por 100 pacientes vigilados. Fueron incluidos 350 pacientes.

Resultados: La tasa de incidencia de NAVM fue de 19,2 / 1.000 días de VM. Los pacientes que presentaron NAVM tuvieron un promedio de edad de 53 años, el $63 \%$ de los pacientes correspondió al sexo masculino y $37 \%$ femenino, el diagnóstico de ingreso más frecuente fueron choque séptico/sepsis grave (36\%), enfermedades crónicas (32\%) y cirugía mayor (20\%). Los microorganismos más frecuentes en NAVM, fueron bacilos Gram negativos, con predominio del Acinetobacter baumannii complex (33\%) y Pseudomona aeruginosa (33\%), y K. pneumoniae (16\%) de los cuales el $100 \%$ de Acinetobacter spp, el $21 \%$ de P. aeruginosa fueron multirresistentes, el $70 \%$ de las K. pneumoniae fueron mutirresistentes productores de Betalactamasa de espectro extendido (BLEE) muestran resistencia a las cefalosporina y otras productoras de Carbapenemasa, Conclusiones: En conclusión este estudio demostró que población estudiada corresponde al promedio de edad de 53 años, el mayor porcentaje de los pacientes con infección asociada a la ventilación mecánica corresponde al sexo masculino. El diagnóstico de ingreso más frecuente fue el Choque séptico/ sepsis grave, la tasa de incidencia de NAVM fue elevada. Los microorganismos causante de las neumonías asociadas a la ventilación mecánica fueron los bacilos Gram negativos, con predominio el Acinetobacter baumannii complex y Pseudomona aeruginosa. El estudio determino una elevada frecuencia de gérmenes multiresistentes, incluyendo gérmenes productoras de carbapenemasa, para lo cual es fundamental la implementación de medidas preventivas.

Existen muchos factores de riesgos tales como: adherencia a la técnica aséptica, intubación y aspiración, lavado de manos, aislamiento de contacto, así como presencia de microorganismos multirresistentes, entre otras. Varios estudios muestran que la asociación entre el uso previo de antimicrobianos y el desarrollo de microorganismos multirresistentes, se encuentra entre las prácticas clínicas que deben ser restringidas y racionalizadas para reducir el riesgo asociado a la mortalidad. Se debe implementar medidas costo- efectivas que disminuyan la transmisión y mejorar la vigilancia de agentes microbiológicos.

Palabras clave: incidencia, infección, neumonía. 


\section{Referencias}

Barros, L. M., Bento, J. N. C., Caetano, J. A, Moreira, R. A.N., Pereira, F. G. F., Frota, N. M., et al. (2012). Prevalência de micro-organismo e sensibilidade antimicrobiana de infecções hospitalares em unidade de terapia intensiva de hospital público no Brasil. Rev Ciênc Farm Básica Apl., 33(3):429-35.

Luna, C. M., Monteverde, A., Rodríguez, A., Apezte, C., Zabert, G., Ilutovich, S. (2005). Neumonía intrahospitalaria: guía clínica aplicable a Latinoamérica preparada en común por diferentes especialistas. Arch Bron coneumol., 41(8):439-56.

Navarro Rodríguez, Z., Safonts Ferrer, J. R., Usatorres, Y. G. \& Porto Castellanos, M. R. (2013). Factores de pronóstico relacionados con la mortalidad por neumonía asociada a ventilación mecánica. Medisan, 17(1), 67-74.

Organización Mundial de la Salud. (2017). Una atención más limpia es una atención más segura. Recuperado de http://www.who.int/gpsc/ background/es/ 